\title{
Percutaneous Coronary Revascularization after Out-of-Hospital Cardiac Arrest: A Review of the Literature and a Case Series
}

\author{
Francesca Scavelli ${ }^{1}$, Iside Cartella ${ }^{1,2}$, Claudio Montalto ${ }^{1}$, Jacopo Andrea Oreglia ${ }^{1}$, Luca Villanova ${ }^{1}$, \\ Laura Garatti $^{1}$, Claudia Colombo ${ }^{1}$, Alice Sacco ${ }^{1} \mathbb{D}$ and Nuccia Morici ${ }^{1, *}$
}

1 Department of Cardiology and De Gasperis Cardio Center, ASST Grande Ospedale Metropolitano Niguarda 20162 Milan, Italy; francesca.scavelli@ospedaleniguarda.it (F.S.); iside.cartella@ospedaleniguarda.it (I.C.); claudio.montalto@ospedaleniguarda.it (C.M.); jacopoandrea.oreglia@ospedaleniguarda.it (J.A.O.); luca.villanova@ospedaleniguarda.it (L.V.); laura.garatti@ospedaleniguarda.it (L.G.); claudia.colombo@ospedaleniguarda.it (C.C.); alice.sacco@ospedaleniguarda.it (A.S.)

2 School of Medicine and Surgery, University of Milano Bicocca, 20126 Milan, Italy

* Correspondence: nuccia.morici@ospedaleniguarda.it; Tel.: +39-0264442565

check for updates

Citation: Scavelli, F.; Cartella, I.; Montalto, C.; Oreglia, J.A.; Villanova, L.; Garatti, L.; Colombo, C.; Sacco, A.; Morici, N. Percutaneous Coronary Revascularization after Out-ofHospital Cardiac Arrest: A Review of the Literature and a Case Series. I. Clin. Med. 2022, 11, 1395. https:// doi.org/10.3390/jcm11051395

Academic Editor: Tim A. Fischell

Received: 25 January 2022

Accepted: 1 March 2022

Published: 3 March 2022

Publisher's Note: MDPI stays neutral with regard to jurisdictional claims in published maps and institutional affiliations.

Copyright: (C) 2022 by the authors. Licensee MDPI, Basel, Switzerland. This article is an open access article distributed under the terms and conditions of the Creative Commons Attribution (CC BY) license (https:// creativecommons.org/licenses/by/ $4.0 /)$.

\begin{abstract}
Out-of-hospital cardiac arrest (OHCA) is still associated with high mortality and severe complications, despite major treatment advances in this field. Ischemic heart disease is a common cause of OHCA, and current guidelines clearly recommend performing immediate coronary angiography $(\mathrm{CAG})$ in patients whose post-resuscitation electrocardiogram shows ST-segment elevation (STE). Contrarily, the optimal approach and the advantage of early revascularization in cases of no STE is less clear, and decisions are often based on the individual experience of the center. Numerous studies have been conducted on this topic and have provided contradictory evidence; however, more recently, results from several randomized clinical trials have suggested that performing early CAG has no impact on overall survival in patients without STE.
\end{abstract}

Keywords: out-of-hospital cardiac arrest; percutaneous coronary revascularization; no ST-segment elevation

\section{Introduction}

Despite advances in percutaneous coronary revascularization and intensive care unit (ICU) management, out-of-hospital cardiac arrest (OHCA) remains associated with high mortality and severe neurological complications [1]. A study reported mortality of approximately $40 \%$ among patients who had been successfully resuscitated after OHCA due to ventricular fibrillation (VF) or pulseless ventricular tachycardia (VT) [2].

Even worse outcomes have been associated with OHCA with non-shockable rhythms of presentation [3].

The prognosis of the resuscitated patient after return of spontaneous circulation (ROSC) is conditioned by "post-cardiac arrest syndrome". This syndrome comprises anoxic brain injury, post-cardiac arrest myocardial dysfunction, systemic ischemia/reperfusion response, and persistent precipitating pathology. The contribution of each of these components in an individual patient depends on various factors, including prearrest comorbidities, duration of the ischemic insult, and cause of the cardiac arrest. Anoxic brain injury is a major cause of morbidity and mortality, and is responsible for approximately two thirds of deaths in the post-cardiac arrest period; the second cause of mortality is represented by progressive haemodynamic deterioration [4].

One important advance in post-ROSC management is the use of therapeutic hypothermia (TH). The introduction of $\mathrm{TH}$ consists of the induction and maintenance of a body temperature between 32 and $34{ }^{\circ} \mathrm{C}$ for $24 \mathrm{~h}$ in patients who remain in a comatose state after ROSC. An Australian study by Bernard et al. and a European study by the Hypothermia After Cardiac Arrest (HACA) working group documented that the use of $\mathrm{TH}$, in patients 
with OHCA due to ventricular fibrillation, was associated with clinically significant neurological improvement and a 14\% improvement in survival 6 months after resuscitation, compared with the control group without hypothermia induction ( $59 \%$ vs. $45 \%, p<0.02$ ) [5]. However, it is controversial whether TH might trigger infectious complications through a pro-inflammatory effect (including sepsis) or by creating a "sepsis-like" syndrome via an increase in pro-inflammatory cytokines, including interleukin (IL)- $1 \beta$, IL-8, and tumor necrosis factor (TNF)- $\alpha[6]$.

A significant correlation has been demonstrated between chemokine (C-C motif) ligand 5 (CCL5), also known as regulated on activation, normal $\mathrm{T}$ cell expressed and secreted (RANTES), IL-1 $\beta$ level, and mortality risk in patients with acute coronary syndromes [7]. Podolec et al. reported that TH leads to a rapid reduction in CCL5/RANTES levels, which might have a beneficial effect on decreasing the inflammatory response. The same effect was observed for IL-1 $\beta$ during TH. Although CCL5/RANTES levels correlate with cardiac injury and heart failure markers and they decrease during $\mathrm{TH}$, they failed to predict early and late mortality. In contrast, IL-1 $\beta$ level was associated with 180-day survival [8].

There is uncertainty regarding the applicability of TH to patients in cardiac arrest in whom the initial cardiac rhythm is asystole or pulseless electric activity. These patients have significantly poorer outcomes compared with patients with an initial cardiac rhythm of VF/VT.

Recommended postresuscitation care includes, in addition to targeted temperature management, vital-organ support, and treatment of the underlying cause of the arrest. However, the cause of arrest is often unclear immediately after the event, and the lack of a definitive diagnosis can lead to uncertainty regarding the appropriate treatment.

Ischemic heart disease is often associated with OHCA and different studies on patients undergoing coronary angiography (CAG) following a cardiac arrest have reported a variable incidence of coronary artery disease (CAD), acute occlusion, or evidence of plaque rupture. Significant CAD has been described to be present in up to $70 \%$ of patients; however, there was an identifiable culprit lesion in approximately $50 \%$ of them [9-12].

The European Society of Cardiology (ESC) and American Heart Association/American College of Cardiology (AHA/ACC) guidelines clearly state that in the case of cardiac arrest and ST-segment elevation (STE) on electrocardiogram (ECG) after ROSC, immediate CAG and revascularization should be performed in order to reduce mortality and improve patient outcomes $[13,14]$. However, the cause of the arrest is not always obvious, and in the absence of STE the role of immediate CAG is still a matter of debate. Furthermore, the predictive value of the post-resuscitation ECG in diagnosing acute myocardial injury has often been questioned [15]. In different studies, patients without STE following a cardiac arrest had an acute coronary occlusion at the $\mathrm{CAG}$, with reported prevalence varying from 17 to $33 \%[9,16,17]$.

\section{Clinical Studies}

Many studies have been published on this topic and have provided conflicting evidence.

Kern et al. reported that early CAG is associated with improved functional outcomes among resuscitated patients of cardiac arrest, regardless of ECG presentation. Nevertheless, similar survival has been observed in patients with and without STE [18]. Improved survival associated with immediate CAG was instead described by Dumas et al. in the case where extracardiac etiology for the arrest is not clearly identifiable, independent of the post-resuscitation ECG pattern. However, their analysis included a significant proportion of patients with STE for whom the benefit of early revascularization was fully recognized [19]. In contrast, Hollenbeck et al. found that a significantly decreased mortality was associated with the use of early CAG, even after excluding patients with STE from their cohort. In their study, coherent with the previously reported data, $27 \%$ of patients were found to have an acute coronary occlusion in the absence of STE on ECG [15]. A similar result was described by Elfwén et al. who reported an improvement in short- and long-term survival with a one-year follow-up [20]. 
These studies have several limitations. The observational design and the absence of randomization may introduce a selection bias, since the indication to perform early CAG may be influenced by the clinical presentation of the patient and the individual judgment of the physician. Moreover, there is a lack of standardized definitions of early and late $\mathrm{CAG}$, and timing to catheterization was variable in the selected patients.

On the contrary, more robust evidence comes from studies suggesting that performing early CAG has no impact on the overall survival in patients without STE.

In the randomized, multi-center COACT trial (Coronary angiography after cardiac arrest without ST-segment elevation), 552 patients with successfully resuscitated OHCA who were unconscious after ROSC, with initial shockable rhythm and no STE at the ECG, were randomized to immediate (median $0.8 \mathrm{~h}$ ) or delayed (median $119.9 \mathrm{~h}$ ) CAG (coronary angiography was performed after neurologic recovery). CAG was performed in 97.1\% of the immediate angiography group and in $64.9 \%$ of the delayed angiography group. At 90 days, 176 of 273 patients (64.5\%) in the immediate angiography group and 178 of 265 patients $(67.2 \%)$ in the delayed angiography group were alive (odds ratio, $0.89 ; 95 \%$ confidence interval (CI), 0.62 to $1.27 ; p=0.51)$. No difference was demonstrated in the number of deaths at one year between the two groups and in the remaining secondary end points (survival at 90 days with good cerebral performance or mild or moderate disability, myocardial injury, duration of catecholamine support, markers of shock, recurrence of ventricular tachycardia, duration of mechanical ventilation, major bleeding, occurrence of acute kidney injury, need for renal-replacement therapy, time to target temperature, and neurologic status at discharge from the ICU). In this study, CAD was found in $64.5 \%$ of patients who underwent immediate CAG. However, the vast majority of patients had stable coronary artery lesions, and thrombotic occlusions were encountered in only 5.0\% of patients. This might explain results, since percutaneous coronary intervention (PCI) is associated with improved outcomes in patients with acute thrombotic coronary occlusion (e.g., in patients with STEMI). Another reason for the lack of benefit of early coronary intervention may be that the majority of non-survivors died of neurologic complications after the cardiac arrest [1,21].

Similar results are provided by the multi-center trial TOMAHAWK (Angiography after out-of-hospital cardiac arrest without ST-segment elevation), conducted on 554 patients $\geq 30$ years of age with ROSC after OHCA and without STE on post-resuscitation ECG [22]. The study randomized patients - regardless of the rhythm of onset (shockable or nonshockable)—with immediate (median $2.9 \mathrm{~h}$ ) or delayed (median $46.9 \mathrm{~h}$ ) CAG. In the latter group, CAG was postponed after the first $24 \mathrm{~h}$ of hospitalization (except in the case of clinical worsening with electrical instability, cardiogenic shock or the appearance of STsegment elevation). CAG was performed in $95 \%$ of patients randomized to immediate CAG and in $62 \%$ of the delayed group. PCI was performed in $37.2 \%$ of cases undergoing immediate CAG and in $43.2 \%$ of those with delayed CAG. The primary end point was death from any cause at 30 days, which occurred in $54 \%$ of patients undergoing urgent CAG and $46 \%$ in the control arm (hazard ratio (HR) 1.28; confidence interval (CI) $95 \%$ $1.00-1.63 ; p=0.06)$. The secondary end point of death from any cause or severe neurologic deficit, occurred more frequently in the immediate CAG arm (64.3\% vs. 55.6\%; relative risk $1.16,95 \%$ CI 1.00-1.34).

The results of the COACT and TOMAHAWK trial are consistent with the results of several randomized trials that showed no survival benefit of immediate CAG as compared with delayed CAG in patients with myocardial infarction without STE who had not presented with cardiac arrest [23-26].

Furthermore, the recently published meta-analysis by Verma et al., conducted on 11 studies enrolling 3581 patients, showed no significant difference in mortality at 30 days, neurological outcome, or rate of revascularization between early or delayed CAG among patients with OHCA without STE. Moreover, 30-day mortality was rather related to patients' comorbidities-namely, diabetes mellitus, chronic renal failure, previous revascularization and lactate level—suggesting that patient selection is crucial to appropriately identify those 
who would benefit from revascularization. Once more, a limitation of the analysis was that the terminology for early and nonearly CAG was variable in the included studies; moreover, revascularization related complications were not analyzed, limiting discussion about peri-procedural outcomes [27].

Following results from the COACT trial, ESC guidelines of 2020 suggest that, in patients with OHCA and no STE or cardiogenic shock, an unselected immediate invasive strategy $(<2 \mathrm{~h})$ is not superior over a delayed one, and that the management of patients needs to be individualized according to their hemodynamic and neurological status [28].

Several randomized clinical trials are still ongoing [29-33]. Results from pilot studies from the DISCO (Direct or subacute coronary angiography in out-of-hospital cardiac arrest), ARREST trial (A randomized trial of expedited transfer to a cardiac arrest center for nonSTE ventricular fibrillation OHCA) and from the prematurely terminated PEARL trial (Early coronary angiography versus delayed coronary angiography) are already available and confirmed no significant difference in mortality between early and delayed CAG in OHCA without STE (Table 1).

Table 1. Randomized clinical trials comparing early and delayed CAG in patients with OHCA without STE on post-resuscitation ECG.

\begin{tabular}{|c|c|c|c|}
\hline Trial & Patients1 & Primary Outcome & Results \\
\hline $\begin{array}{c}\text { COACT (Coronary angiography after cardiac } \\
\text { arrest without STE) [1] } \\
\text { NTR4973 }\end{array}$ & 552 & $\begin{array}{c}\text { Survival at } 90 \text { days and } \\
\text { one year }\end{array}$ & No difference \\
\hline $\begin{array}{c}\text { TOMAHAWK (Angiography after Out-of-Hospital } \\
\text { Cardiac Arrest without STE) [22] } \\
\text { NCT02750462 }\end{array}$ & 554 & Survival at 30 days & No difference \\
\hline $\begin{array}{c}\text { DISCO (Direct or subacute coronary angiography } \\
\text { in OHCA) [31] } \\
\text { NCT02309151 }\end{array}$ & 1006 & Survival at 30 days & $\begin{array}{l}\text { Ongoing } \\
\text { PILOT (79 patients): } \\
\text { no difference }\end{array}$ \\
\hline $\begin{array}{c}\text { EMERGE (Emergency versus delayed coronary } \\
\text { angiogram in survivors of OHCA) [29] } \\
\text { NCT02876458 }\end{array}$ & 970 & $\begin{array}{l}\text { Survival at } 180 \text { days and } \\
\text { neurological outcome }\end{array}$ & Ongoing \\
\hline $\begin{array}{l}\text { ARREST (Randomized trial of expedited transfer } \\
\text { to a cardiac arrest center for non-STE OHCA) [30] } \\
\text { NCT03872960 }\end{array}$ & 860 & Survival at 30 days & $\begin{array}{l}\text { Ongoing } \\
\text { PILOT (63 patients): } \\
\text { no difference }\end{array}$ \\
\hline $\begin{array}{c}\text { COUPE (Coronarography in OHCA) [33] } \\
\text { NCT02641626 }\end{array}$ & 166 & $\begin{array}{l}\text { In-hospital survival and } \\
\text { neurological outcome }\end{array}$ & Ongoing \\
\hline $\begin{array}{c}\text { PEARL (Early coronary angiography versus } \\
\text { delayed coronary angiography) [32] } \\
\text { NCT02387398 }\end{array}$ & 99 & Survival at 180 days & $\begin{array}{l}\text { Prematurely terminated } \\
\text { (underpowered): } \\
\text { no difference }\end{array}$ \\
\hline
\end{tabular}

CAG: coronary angiography, OHCA: Out-of-hospital cardiac arrest, ECG: electrocardiogram.

\section{Case Series}

- A 55-year-old man with OHCA associated with shockable heart rhythm that occurred during physical exercise.

The patient had no previous medical history and no family history of cardiac diseases or sudden cardiac death. There was no history of alcohol abuse, recreational drug use or toxic environmental exposure. He had been in good state of health for the entire day, and he was jogging when he suddenly lost consciousness with consequent frontal cranial trauma. Cardiopulmonary resuscitation (CPR) was immediately performed by bystanders and emergency medical service arrived after approximately $10 \mathrm{~min}$. The heart rhythm was identified as shockable with the semi-automatic defibrillator and sinus rhythm was restored after one shock. Emergency endotracheal intubation was performed, and the patient arrived in our emergency room approximately $40 \mathrm{~min}$ after the initial arrest. 
The ECG after ROSC showed sinus rhythm (Figure 1A), normal atrio-ventricular conduction, and no evidence of ischemic signs. ECG was repeated after positioning of the right precordial leads in the second intercostal space, and did not reveal a Brugada pattern morphology.
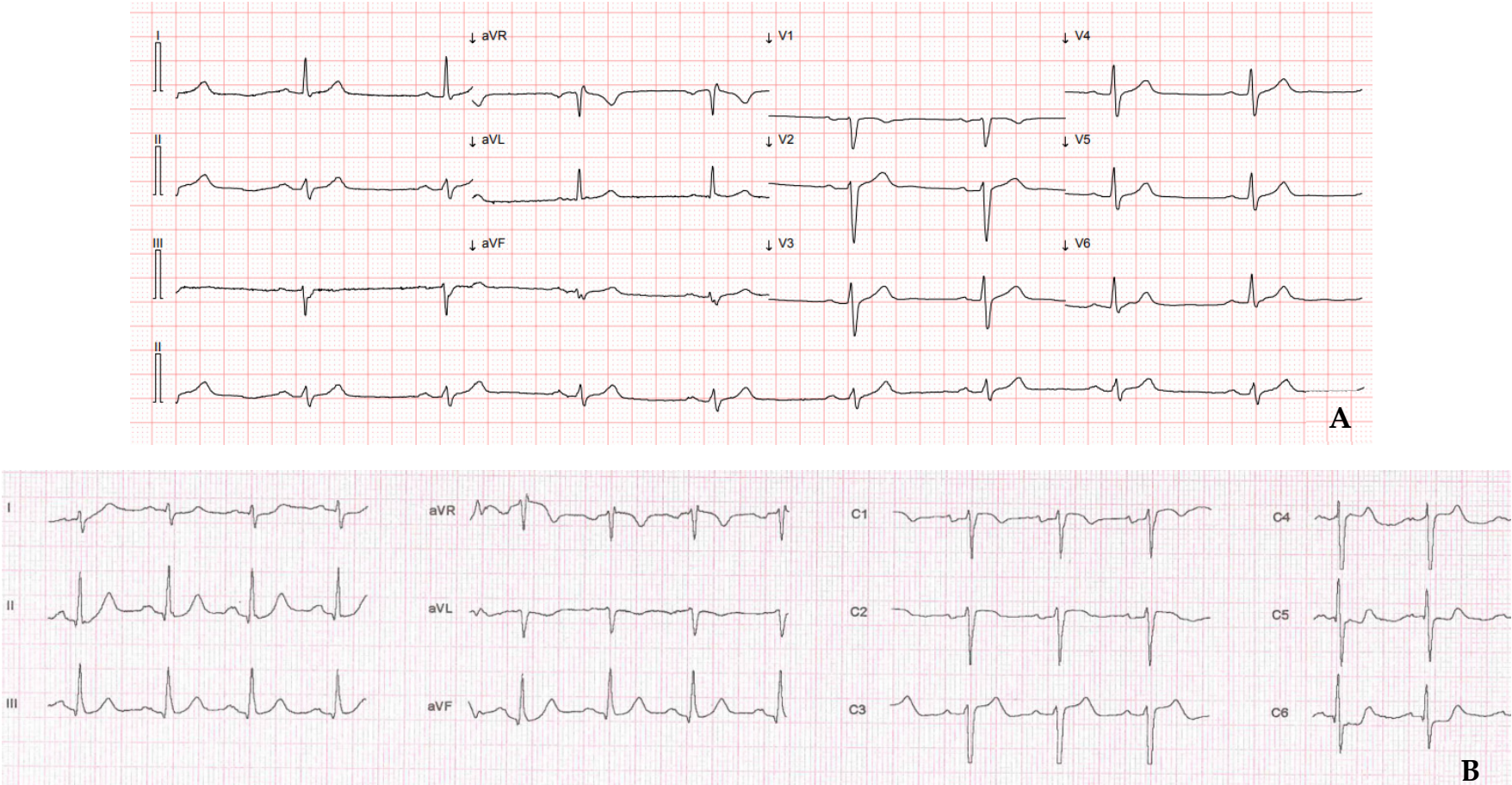

Figure 1. Electrocardiogram after restoration of spontaneous circulation. (A) Case 1: no ischemic signs are evident; (B) Case 2: ST-segment depression in leads V5-V6.

Cardiac ultrasound images showed normal size of the left ventricle, and hypokinesia of the mid and apical interventricular septum with mild reduction in ejection fraction that was $45 \%$. There was ectasia of the aortic root and ascending aorta (42 mm), a normal right ventricle, no significant valvular defects, and no pericardial effusion.

Brain computed tomography (CT), performed without administration of intravenous contrast medium, revealed no evidence of infarct, intracranial hemorrhage, or mass lesions.

Diagnostic CAG performed in emergency (Figure 2A) showed two-vessel CAD with chronic total occlusion (CTO) of the left anterior descending artery (LDA), and critical stenosis of the right coronary artery (RCA) and posterolateral artery (PLA) of the circumflex coronary artery. No culprit lesion was identified, and revascularization was not performed at that time.

The patient was transferred to our ICU. Laboratory tests showed normal complete blood count, renal function, thyroid hormones, and serum electrolytes. Creatine phosphokinase levels were within the normal limit and high-sensitive troponin-T was slightly elevated at $35.5 \mathrm{ng} / \mathrm{L}(0.0-14.0)$. A mild alteration in hepatic function was detected with a total bilirubin of $1.37 \mathrm{mg} / \mathrm{dL}(0.25-1.00)$ and alanine aminotransferase of $87 \mathrm{U} / \mathrm{L}$ (3-45). The clinical neurological examination was normal, as well as the brain CT scan performed after $24 \mathrm{~h}$. Extubation was performed after three days due to psychomotor agitation and complete restoration of neurocognitive status was observed after one week. The patient had very high blood pressure values, and hypertensive treatment with combination therapy was initiated.

Revascularization was performed after one week from the cardiac arrest. In the first procedure, PCI with placement of one drug eluting stent (DES) in the RCA and one DES in the PLA was performed. Complete revascularization was obtained after a further 8 
days with anterograde recanalization of the CTO of the LDA with PCI and placement of one DES.
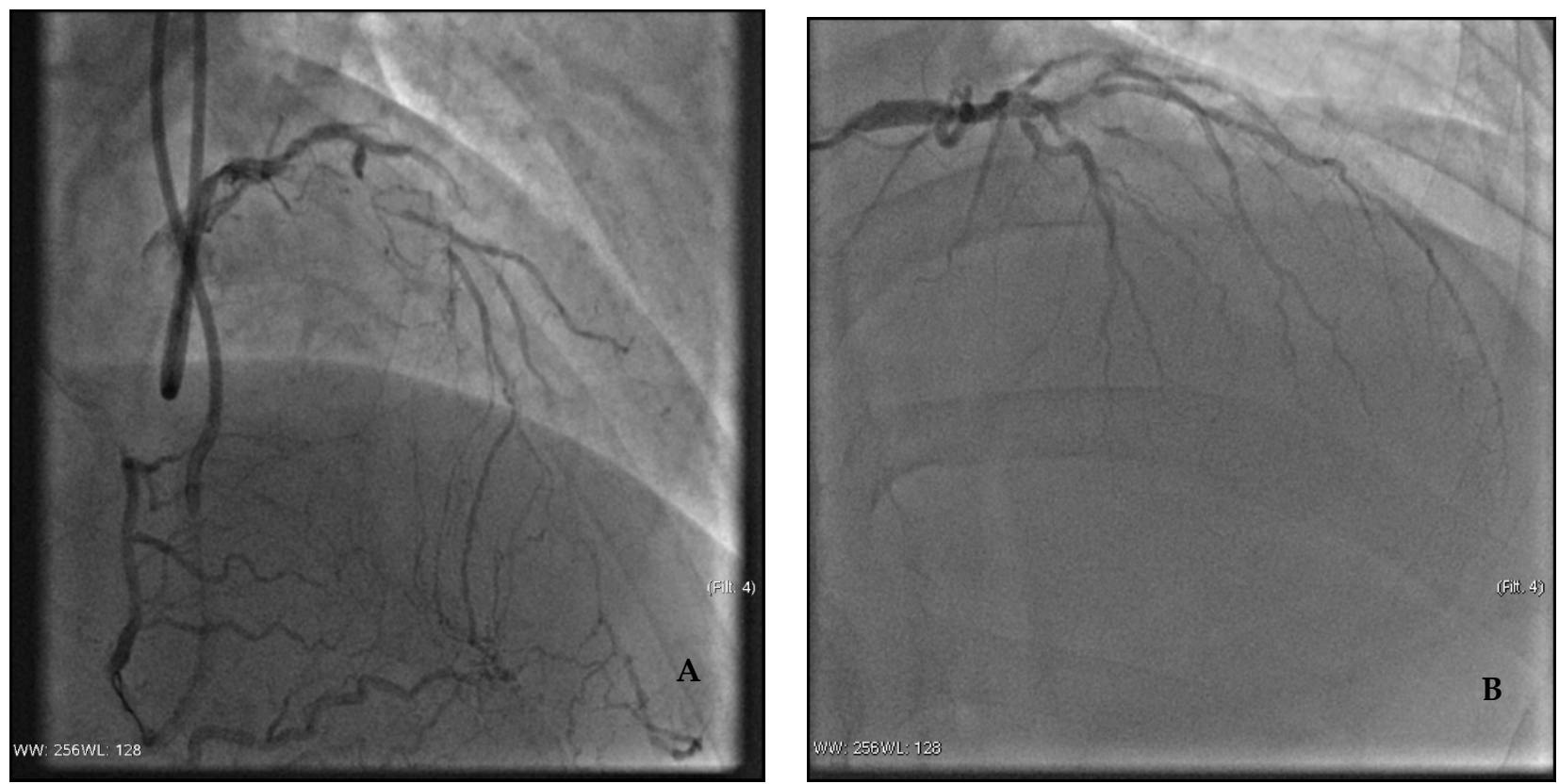

Figure 2. Coronary angiography. (A) Case 1: chronic total occlusion of the left anterior descending artery; (B) Case 2: chronic total occlusion of the left anterior descending artery in its middle tract and critical ostial stenosis of the first diagonal branch.

An implantable cardioverter device (ICD) was positioned for secondary prevention. Echocardiogram before discharge showed normal cardiac function with no abnormalities in segmental wall motion.

At one-year follow-up, no intervention of the ICD and arrhythmic events had occurred. The patient had a normal echocardiogram and no symptoms of ischemic heart disease.

- A 51-year-old man experienced OHCA, not preceded by prodromes, while playing a tennis match.

This gentleman had a past medical history of mild hypertension and no other cardiovascular risk factors, cardiac diseases, or family history of cardiac pathologies. After the cardiac arrest, he immediately received CPR by a bystander, and ROSC was achieved after one shock with the semi-automatic external defibrillator. Emergency medical service arrived in nearly $10 \mathrm{~min}$, the patient was transferred to our hospital after endotracheal intubation, and was placed on mechanical ventilation.

At arrival in our ICU, the ECG showed sinus rhythm, normal atrio-ventricular conduction and ST-segment depression in leads V5-V6. Bedside transthoracic echocardiogram demonstrated a structurally normal heart with preserved left ventricular systolic function; however, hypokinesis of the distal segment of the anterior and lateral wall was evident.

On suspicion of acute coronary syndrome, emergency CAG was performed via radial artery approach (Figure 2B). Angiography revealed a three-vessel CAD with CTO of the LDA in its middle tract, and critical ostial stenosis of the first diagonal branch and of the circumflex coronary artery (LCx). PCI was performed with anterograde recanalization of the CTO of the LDA, and placement of three DESs at the level of the bifurcation with the first diagonal branch.

Blood tests revealed elevated markers of myocardial injury with an hs-Tnt of $412 \mathrm{ng} / \mathrm{L}$ $(0.0-14.0 \mathrm{ng} / \mathrm{L})$. No other alterations were present. No significant increase in hs-Tnt was observed after the procedure.

Extubation was performed during the second day of stay, after evidence of a preserved neurocognitive status with sedation interruption and a neurological wake-up test. Complete 
revascularization was achieved after 11 days with PCI and the placement of three DESs in the LCx.

Lastly, cardiac magnetic resonance (CMR) was performed before discharge. Hypokinesia of the anterior and lateral wall with an overall preserved ejection fraction was confirmed. T2-weighted short-tau inversion recovery (T2w-STIR) showed signal hyperintensity at the level of the mid-low segment of the anterior wall, consistent with the presence of edema (Figure 3). Furthermore, late gadolinium enhancement (LGE) with an ischemic pattern was present in the anterior wall and in the apex, with a subendocardial distribution with variable transmural extension, confirming the diagnosis of acute anterior myocardial infarction (Figure 4).
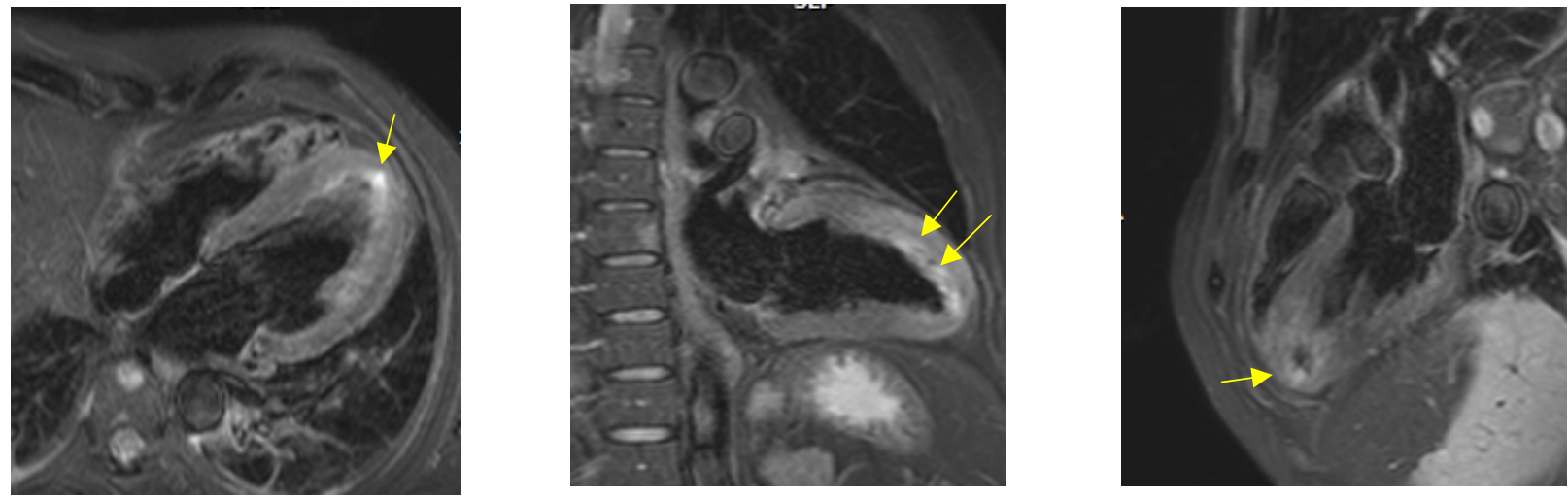

Figure 3. Case 2: cardiac magnetic resonance: T2w-STIR. Arrows indicate the presence of edema.
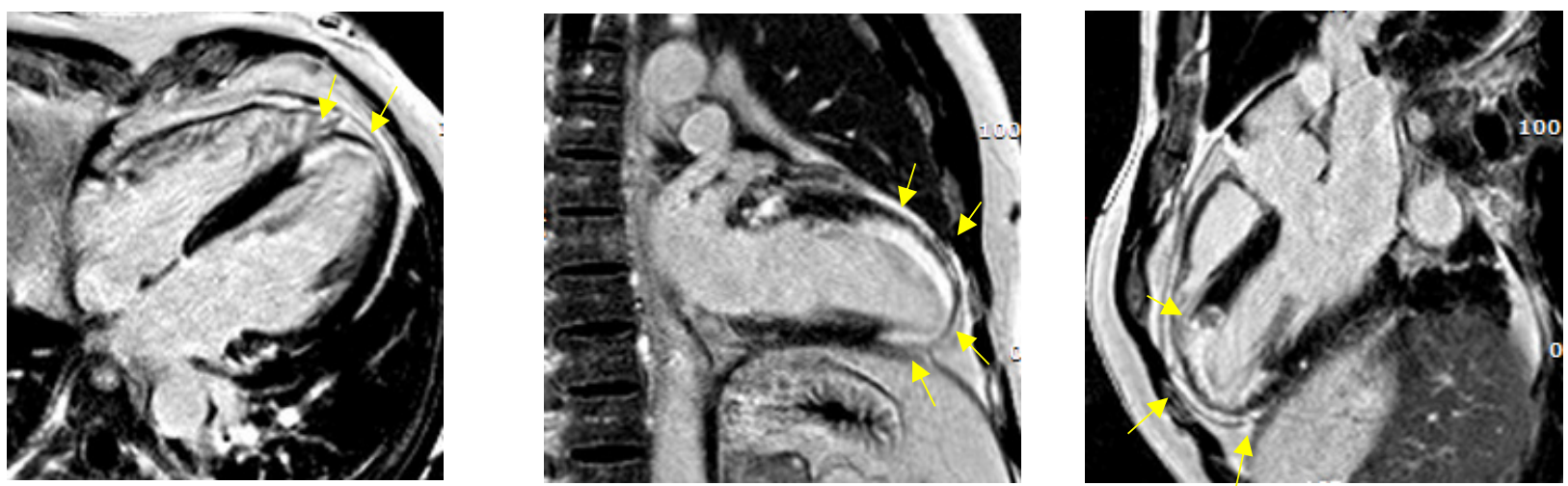

Figure 4. Case 2: cardiac magnetic resonance: arrows indicate late gadolinium enhancement (LGE).

As in the previous case, after one year, the patient was asymptomatic and did not experience any arrhythmic episode.

\section{Discussion}

The aforementioned cases offer different points of discussion. We presented two patients with a similar cardiovascular risk profile and no previous history of cardiac events. Both of them experienced OHCA with a shockable rhythm during physical exercise. However, the first patient had a non-ischemic ECG post-ROSC and a non-significant increase in markers of myocardial injury, while the second patient presented with ischemic ECG changes and contextual increase in troponin that configured the clinical scenario of an acute coronary syndrome although without evidence of an STE.

Clearly, cardiac biomarkers are not immediately available, and the decision to perform emergent CAG and eventual revascularization in these cases is always based on the ECG and clinical evaluation of the patient. 
Both patients underwent immediate CAG, yet, according to current guidelines, this decision was definitely questionable, in particular in the first case. No clear culprit lesion was identified and, considering the overall clinical scenario, in the first patient no immediate revascularization was attempted, while in the second, retrograde recanalization of a CTO was performed in emergency. Evidence of at least one CTO in patients with OHCA and no STE is not infrequent and, as reported in recent studies, it is found in approximately one-fourth of cases. Currently, it is not well established whether these CTOs are just bystanders, or if they contribute to the ischemic burden and should be considered for revascularization [18]. Nevertheless, at long-term follow-up, patients with non-revascularized CTOs have a worse outcome compared with those revascularized, with a three-fold risk of sudden cardiac death and ventricular arrythmias [34]. Moreover, in patients with cardiac arrest and acute coronary syndrome, the presence of a CTO is significantly associated with higher in-hospital mortality [35].

With regards to ICD implantation for secondary prevention, ESC and AHA/ACC guidelines recommend it in patients with a documented VF or VT causing haemodynamic instability, in the absence of an identified reversible cause [36,37]. The first patient did not have a diagnosis of an acute coronary syndrome and the cause of the cardiac arrest was not completely clear, so indication to ICD implantation was given for secondary prevention. Contrarily, the second patient experienced an acute coronary event, and even in the absence of a clear culprit lesion, an ischemic pattern with an extent of transmural LGE was evident at the CMR. Considering that complete revascularization was achieved, ICD was not implanted in this case.

\section{Conclusions}

The presented cases demonstrate how, in daily practice, indications to perform immediate CAG are often based on individual decisions, and that clear guidelines are still missing. Many randomized clinical trials are still ongoing, and results are needed to provide a standardized approach to guide patient selection criteria.

According to recent evidence, in patients that survive an OHCA and present with a non-STE post-resuscitation ECG, performing early versus delayed CAG provides no benefits in terms of short-term mortality or neurological outcome. In the resuscitated OHCA, short and long-term prognosis is substantially conditioned by two factors: neurological damage and cardiac damage. An immediate invasive strategy may affect the latter, especially when the onset is characterized by cardiogenic shock or hemodynamic instability (conditions that excluded randomization in TOMAHAWK and COACT, but not enrollment in many registry studies), but it is unlikely to have an effect on the former. Anoxic injury and neurologic impairment were the predominant causes of death in the TOMAHAWK study, as well as in the COACT study. In subjects with significant neurological impairment upon arrival at the hospital (in the TOMAHAWK study the median of the Glasgow Coma Scale score was 3), indicative of a very advanced situation, many invasive procedures could be futile, or even potentially harmful.

Author Contributions: Manuscript writing and revision, F.S. and I.C.; critical revision and final approval of the article, C.M., N.M., A.S. and J.A.O.; critical revision C.C., L.G. and L.V. All authors have read and agreed to the published version of the manuscript.

Funding: This research received no external funding.

Institutional Review Board Statement: Not applicable.

Informed Consent Statement: Written informed consent has been obtained from the patients to publish this paper.

Conflicts of Interest: The authors declare no conflict of interest. 


\section{References}

1. Lemkes, J.S.; Janssens, G.N.; van der Hoeven, N.W.; Jewbali, L.S.D.; Dubois, E.A.; Meuwissen, M.; Rijpstra, T.A.; Bosker, H.A.; Blans, M.J.; Bleeker, G.B.; et al. Coronary Angiography after Cardiac Arrest without ST-Segment Elevation. N. Engl. J. Med. 2019, 380, 1397-1407. [CrossRef] [PubMed]

2. Patel, N.; Patel, N.J.; Macon, C.J.; Thakkar, B.; Desai, M.; Rengifo-Moreno, P.; Alfonso, C.E.; Myerburg, R.J.; Bhatt, D.L.; Cohen, M.G. Trends and Outcomes of Coronary Angiography and Percutaneous Coronary Intervention After Out-of-Hospital Cardiac Arrest Associated with Ventricular Fibrillation or Pulseless Ventricular Tachycardia. JAMA Cardiol. 2016, 1, 890-899. [CrossRef] [PubMed]

3. Sasson, C.; Rogers, M.A.M.; Dahl, J.; Kellermann, A.L. Predictors of Survival from Out-of-Hospital Cardiac Arrest: A Systematic Review and Meta-Analysis. Circ. Cardiovasc. Qual. Outcomes 2010, 3, 63-81. [CrossRef] [PubMed]

4. Stub, D.; Bernard, S.; Duffy, S.J.; Kaye, D.M. Post Cardiac Arrest Syndrome: A Review of Therapeutic Strategies. Circulation 2011, 123, 1428-1435. [CrossRef]

5. Hypothermia after Cardiac Arrest Study Group. Mild Therapeutic Hypothermia to Improve the Neurologic Outcome after Cardiac Arrest. N. Engl. J. Med. 2002, 346, 549-556. [CrossRef]

6. Adrie, C.; Adib-Conquy, M.; Laurent, I.; Monchi, M.; Vinsonneau, C.; Fitting, C.; Fraisse, F.; Dinh-Xuan, A.T.; Carli, P.; Spaulding, C.; et al. Successful Cardiopulmonary Resuscitation after Cardiac Arrest as a "Sepsis-like" Syndrome. Circulation 2002, 106, 562-568. [CrossRef]

7. $\quad$ de Jager, S.C.A.; Bongaerts, B.W.C.; Weber, M.; Kraaijeveld, A.O.; Rousch, M.; Dimmeler, S.; van Dieijen-Visser, M.P.; Cleutjens, K.B.J.M.; Nelemans, P.J.; van Berkel, T.J.C.; et al. Chemokines CCL3/MIP 1 Alpha, CCL5/RANTES and CCL18/PARC Are Independent Risk Predictors of Short-Term Mortality in Patients with Acute Coronary Syndromes. PLoS ONE 2012, 7, e45804. [CrossRef]

8. Trąbka-Zawicki, A.; Badacz, R.; Siedliński, M.; Tomala, M.; Bartuś, K.; Legutko, J.; Przewłocki, T.; Żmudka, K.; Kabłak-Ziembicka, A.; Podolec, J. Chemokine RANTES and IL-1 $\beta$ in Mild Therapeutic Hypothermia-Treated Patients after out-of-Hospital Sudden Cardiac Arrest. Postepy Kardiol. Interwencyjnej = Adv. Interv. Cardiol. 2019, 15, 98-106. [CrossRef]

9. Anyfantakis, Z.A.; Baron, G.; Aubry, P.; Himbert, D.; Feldman, L.J.; Juliard, J.M.; Ricard-Hibon, A.; Burnod, A.; Cokkinos, D.v.; Steg, P.G. Acute Coronary Angiographic Findings in Survivors of Out-of-Hospital Cardiac Arrest. Am. Heart J. 2009, 157, 312-318. [CrossRef]

10. Spaulding, C.M.; Joly, L.-M.; Rosenberg, A.; Monchi, M.; Weber, S.N.; Dhainaut, J.-F.A.; Carli, P. Immediate Coronary Angiography in Survivors of Out-of-Hospital Cardiac Arrest. N. Engl. J. Med. 1997, 336, 1629-1633. [CrossRef]

11. Dumas, F.; Cariou, A.; Manzo-Silberman, S.; Grimaldi, D.; Vivien, B.; Rosencher, J.; Empana, J.P.; Carli, P.; Mira, J.P.; Jouven, X.; et al. Immediate Percutaneous Coronary Intervention Is Associated with Better Survival after Out-of-Hospital Cardiac Arrest: Insights from the PROCAT (Parisian Region Out of Hospital Cardiac Arrest) Registry. Circ. Cardiovasc. Interv. 2010, 3, 200-207. [CrossRef] [PubMed]

12. Reynolds, J.C.; Callaway, C.W.; el Khoudary, S.R.; Moore, C.G.; Alvarez, R.J.; Rittenberger, J.C. Coronary Angiography Predicts Improved Outcome Following Cardiac Arrest: Propensity-Adjusted Analysis. J. Intensive Care Med. 2009, 24, 179-186. [CrossRef] [PubMed]

13. Levine, G.N.; Bates, E.R.; Blankenship, J.C.; Bailey, S.R.; Bittl, J.A.; Cercek, B.; Chambers, C.E.; Ellis, S.G.; Guyton, R.A.; Hollenberg, S.M.; et al. 2015 ACC/AHA/SCAI Focused Update on Primary Percutaneous Coronary Intervention for Patients with STElevation Myocardial Infarction: An Update of the 2011 ACCF/AHA/SCAI Guideline for Percutaneous Coronary Intervention and the 2013 ACCF / AHA Guideline for the Management of ST-Elevation Myocardial Infarction: A Report of the American College of Cardiology/American Heart Association Task Force on Clinical Practice Guidelines and the Society for Cardiovascular Angiography and Interventions. Catheter. Cardiovasc. Interv. Off. J. Soc. Card. Angiogr. Interv. 2016, 87, 1001-1019. [CrossRef]

14. Ibanez, B.; James, S.; Agewall, S.; Antunes, M.J.; Bucciarelli-Ducci, C.; Bueno, H.; Caforio, A.L.P.; Crea, F.; Goudevenos, J.A.; Halvorsen, S.; et al. 2017 ESC Guidelines for the Management of Acute Myocardial Infarction in Patients Presenting with ST-Segment Elevation. Eur. Heart J. 2018, 39, 119-177. [CrossRef] [PubMed]

15. Hollenbeck, R.D.; McPherson, J.A.; Mooney, M.R.; Unger, B.T.; Patel, N.C.; McMullan, P.W.; Hsu, C.H.; Seder, D.B.; Kern, K.B. Early Cardiac Catheterization Is Associated with Improved Survival in Comatose Survivors of Cardiac Arrest without STEMI. Resuscitation 2014, 85, 88-95. [CrossRef]

16. Abstract 10305: Clinical and Angiographic Characteristics of Patients Undergoing Percutaneous Coronary Intervention Following Sudden Cardiac Arrest: Insights From the NCDR® I Circulation. Available online: https:/ /www.ahajournals.org/doi/10.1161/ circ.124.suppl_21.A10305 (accessed on 28 December 2021).

17. Radsel, P.; Knafelj, R.; Kocjancic, S.; Noc, M. Angiographic Characteristics of Coronary Disease and Postresuscitation Electrocardiograms in Patients With Aborted Cardiac Arrest Outside a Hospital. Am. J. Cardiol. 2011, 108, 634-638. [CrossRef]

18. Kern, K.B.; Lotun, K.; Patel, N.; Mooney, M.R.; Hollenbeck, R.D.; McPherson, J.A.; McMullan, P.W.; Unger, B.; Hsu, C.H.; Seder D.B. Outcomes of Comatose Cardiac Arrest Survivors With and Without ST-Segment Elevation Myocardial Infarction: Importance of Coronary Angiography. JACC Cardiovasc. Interv. 2015, 8, 1031-1040. [CrossRef]

19. Geri, G.; Dumas, F.; Bougouin, W.; Varenne, O.; Daviaud, F.; Pène, F.; Lamhaut, L.; Chiche, J.D.; Spaulding, C.; Mira, J.P.; et al. Immediate Percutaneous Coronary Intervention Is Associated with Improved Short-and Long-Term Survival after Out-of-Hospital Cardiac Arrest. Circ. Cardiovasc. Interv. 2015, 8, e002303. [CrossRef] 
20. Elfwén, L.; Lagedal, R.; James, S.; Jonsson, M.; Jensen, U.; Ringh, M.; Claesson, A.; Oldgren, J.; Herlitz, J.; Rubertsson, S.; et al. Coronary Angiography in Out-of-Hospital Cardiac Arrest without ST Elevation on ECG-Short- and Long-Term Survival. Am. Heart J. 2018, 200, 90-95. [CrossRef]

21. Lemkes, J.S.; Janssens, G.N.; van der Hoeven, N.W.; Jewbali, L.S.D.; Dubois, E.A.; Meuwissen, M.M.; Rijpstra, T.A.; Bosker, H.A.; Blans, M.J.; Bleeker, G.B.; et al. Coronary Angiography after Cardiac Arrest Without ST Segment Elevation: One-Year Outcomes of the COACT Randomized Clinical Trial. JAMA Cardiol. 2020, 5, 1358-1365. [CrossRef]

22. Desch, S.; Freund, A.; Akin, I.; Behnes, M.; Preusch, M.R.; Zelniker, T.A.; Skurk, C.; Landmesser, U.; Graf, T.; Eitel, I.; et al. Angiography after Out-of-Hospital Cardiac Arrest without ST-Segment Elevation. N. Engl. J. Med. 2021, 385, $2544-2553$. [CrossRef] [PubMed]

23. Milosevic, A.; Vasiljevic-Pokrajcic, Z.; Milasinovic, D.; Marinkovic, J.; Vukcevic, V.; Stefanovic, B.; Asanin, M.; Dikic, M.; Stankovic, S.; Stankovic, G. Immediate Versus Delayed Invasive Intervention for Non-STEMI Patients: The RIDDLE-NSTEMI Study. JACC Cardiovasc. Interv. 2016, 9, 541-549. [CrossRef] [PubMed]

24. Thiele, H.; Rach, J.; Klein, N.; Pfeiffer, D.; Hartmann, A.; Hambrecht, R.; Sick, P.; Eitel, I.; Desch, S.; Schuler, G. Optimal Timing of Invasive Angiography in Stable Non-ST-Elevation Myocardial Infarction: The Leipzig Immediate versus Early and Late PercutaneouS Coronary Intervention TriAl in NSTEMI (LIPSIA-NSTEMI Trial). Eur. Heart J. 2012, 33, 2035-2043. [CrossRef] [PubMed]

25. Riezebos, R.K.; Ronner, E.; ter Bals, E.; Slagboom, T.; Smits, P.C.; ten Berg, J.M.; Kiemeneij, F.; Amoroso, G.; Patterson, M.S.; Suttorp, M.J.; et al. Immediate versus Deferred Coronary Angioplasty in Non-ST-Segment Elevation Acute Coronary Syndromes. Heart (Br. Card. Soc.) 2009, 95, 807-812. [CrossRef]

26. Montalescot, G.; Cayla, G.; Collet, J.P.; Elhadad, S.; Beygui, F.; le Breton, H.; Choussat, R.; Leclercq, F.; Silvain, J.; Duclos, F.; et al. Immediate vs Delayed Intervention for Acute Coronary Syndromes: A Randomized Clinical Trial. JAMA 2009, 302, 947-954. [CrossRef] [PubMed]

27. Coronary Angiography in Out-of-Hospital Cardiac Arrest Patients-American College of Cardiology. Available online: https:/ / www.acc.org/latest-in-cardiology/journal-scans/2020/10/08/19/50/coronary-angiography-in-patients (accessed on 28 December 2021).

28. Collet, J.-P.; Thiele, H.; Barbato, E.; Barthélémy, O.; Bauersachs, J.; Bhatt, D.L.; Dendale, P.; Dorobantu, M.; Edvardsen, T.; Folliguet, T.; et al. 2020 ESC Guidelines for the Management of Acute Coronary Syndromes in Patients Presenting without Persistent ST-Segment ElevationThe Task Force for the Management of Acute Coronary Syndromes in Patients Presenting without Persistent ST-Segment Elevation of the European Society of Cardiology (ESC). Eur. Heart J. 2021, 42, 1289-1367. [CrossRef]

29. Hauw-Berlemont, C.; Lamhaut, L.; Diehl, J.L.; Andreotti, C.; Varenne, O.; Leroux, P.; Lascarrou, J.B.; Guerin, P.; Loeb, T.; Roupie, E.; et al. EMERGEncy versus Delayed Coronary Angiogram in Survivors of Out-of-Hospital Cardiac Arrest with No Obvious Non-Cardiac Cause of Arrest: Design of the EMERGE Trial. Am. Heart J. 2020, 222, 131-138. [CrossRef]

30. Patterson, T.; Perkins, G.D.; Joseph, J.; Wilson, K.; van Dyck, L.; Robertson, S.; Nguyen, H.; McConkey, H.; Whitbread, M.; Fothergill, R.; et al. A Randomised TRial of Expedited Transfer to a Cardiac Arrest Centre for Non-ST Elevation Ventricular Fibrillation out-of-Hospital Cardiac Arrest: The ARREST Pilot Randomised Trial. Resuscitation 2017, 115, 185-191. [CrossRef]

31. Lagedal, R.; Elfwén, L.; James, S.; Oldgren, J.; Erlinge, D.; Östlund, O.; Wallin, E.; Larsson, I.M.; Lilja, G.; Cronberg, T.; et al. Design of DISCO_Direct or Subacute Coronary Angiography in Out-of-Hospital Cardiac Arrest Study. Am. Heart J. 2018, 197, 53-61. [CrossRef]

32. Kern, K.B.; Radsel, P.; Jentzer, J.C.; Seder, D.B.; Lee, K.S.; Lotun, K.; Janardhanan, R.; Stub, D.; Hsu, C.H.; Noc, M. Randomized Pilot Clinical Trial of Early Coronary Angiography Versus No Early Coronary Angiography after Cardiac Arrest without ST-Segment Elevation: The PEARL Study. Circulation 2020, 142, 2002-2012. [CrossRef]

33. Viana-Tejedor, A.; Ariza-Solé, A.; Martínez-Sellés, M.; Jiménez Mena, M.; Vila, M.; García, C.; García Acuña, J.; Bañeras, J.; García Rubira, J.C.; Pérez, P.J.; et al. Role of Coronary Angiography in Patients with a Non-Diagnostic Electrocardiogram Following out of Hospital Cardiac Arrest: Rationale and Design of the Multicentre Randomized Controlled COUPE Trial. Eur. Heart J. Acute Cardiovasc. Care 2020, 9, S131-S137. [CrossRef] [PubMed]

34. Godino, C.; Giannattasio, A.; Scotti, A.; Baldetti, L.; Pivato, C.A.; Munafò, A.; Cappelletti, A.; Beneduce, A.; Melillo, F.; Chiarito, M.; et al. Risk of Cardiac and Sudden Death with and without Revascularisation of a Coronary Chronic Total Occlusion. Heart (Br. Card. Soc.) 2019, 105, 1096-1102. [CrossRef] [PubMed]

35. Shinouchi, K.; Ueda, Y.; Kato, T.; Nishida, H.; Ozaki, T.; Kosugi, S.; Iida, Y.; Toriyama, C.; Ohashi, T.; Nakamura, M.; et al. Relation of Chronic Total Occlusion to In-Hospital Mortality in the Patients with Sudden Cardiac Arrest Due to Acute Coronary Syndrome. Undefined 2019, 123, 1915-1920. [CrossRef] [PubMed]

36. Al-Khatib, S.M.; Stevenson, W.G.; Ackerman, M.J.; Bryant, W.J.; Callans, D.J.; Curtis, A.B.; Deal, B.J.; Dickfeld, T.; Field, M.E.; Fonarow, G.C.; et al. 2017 AHA/ACC/HRS Guideline for Management of Patients With Ventricular Arrhythmias and the Prevention of Sudden Cardiac Death: A Report of the American College of Cardiology/American Heart Association Task Force on Clinical Practice Guidelines and the Heart Rhythm Society. J. Am. Coll. Cardiol. 2018, 72, e91-e220. [CrossRef]

37. Priori, S.G.; Blomstrom-Lundqvist, C.; Mazzanti, A.; Bloma, N.; Borggrefe, M.; Camm, J.; Elliott, P.M.; Fitzsimons, D.; Hatala, R.; Hindricks, G.; et al. 2015 ESC Guidelines for the Management of Patients with Ventricular Arrhythmias and the Prevention of Sudden Cardiac Death the Task Force for the Management of Patients with Ventricular Arrhythmias and the Prevention of Sudden Cardiac Death of the European Society of Cardiology (ESC) Endorsed by: Association for European Paediatric and Congenital Cardiology (AEPC). Eur. Heart J. 2015, 36, 2793-2867. [CrossRef] [PubMed] 